\title{
Unusual case of a large small-bowel enteroenteric fistula successfully closed using purse-string sutures
}

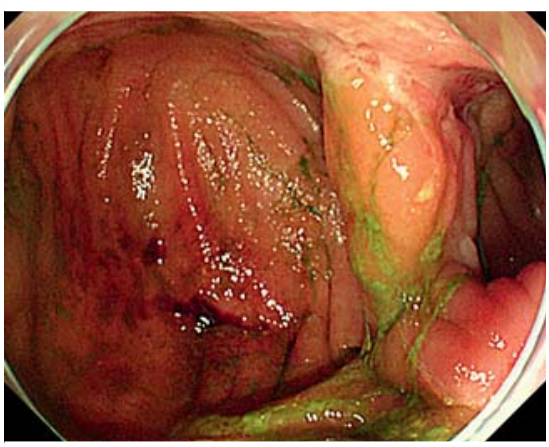

- Fig. 1 A large fistula in the second portion of the duodenum.

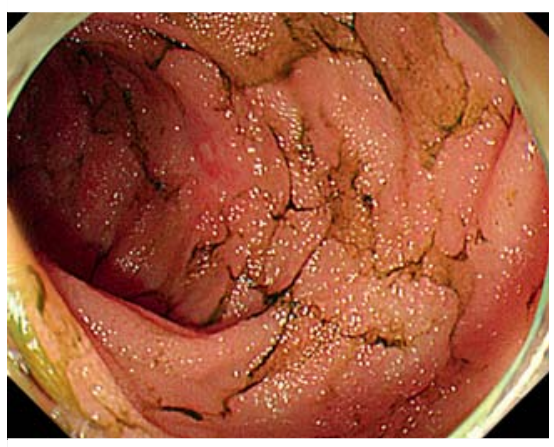

- Fig. 2 The jejunoileal lumen.

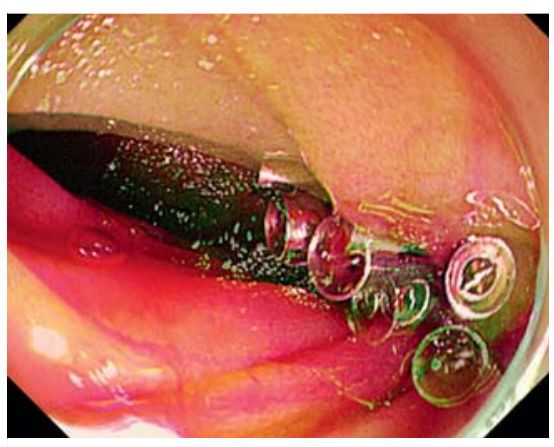

Fig. 3 Closure of the fistula orifice using purse-string sutures.

A 28-year-old man was diagnosed with colonic Crohn's disease with previous symptoms of diarrhea, weight loss, and vomiting 8 years ago. He was continually prescribed sulfasalazine ( $3 \mathrm{~g} /$ day) from

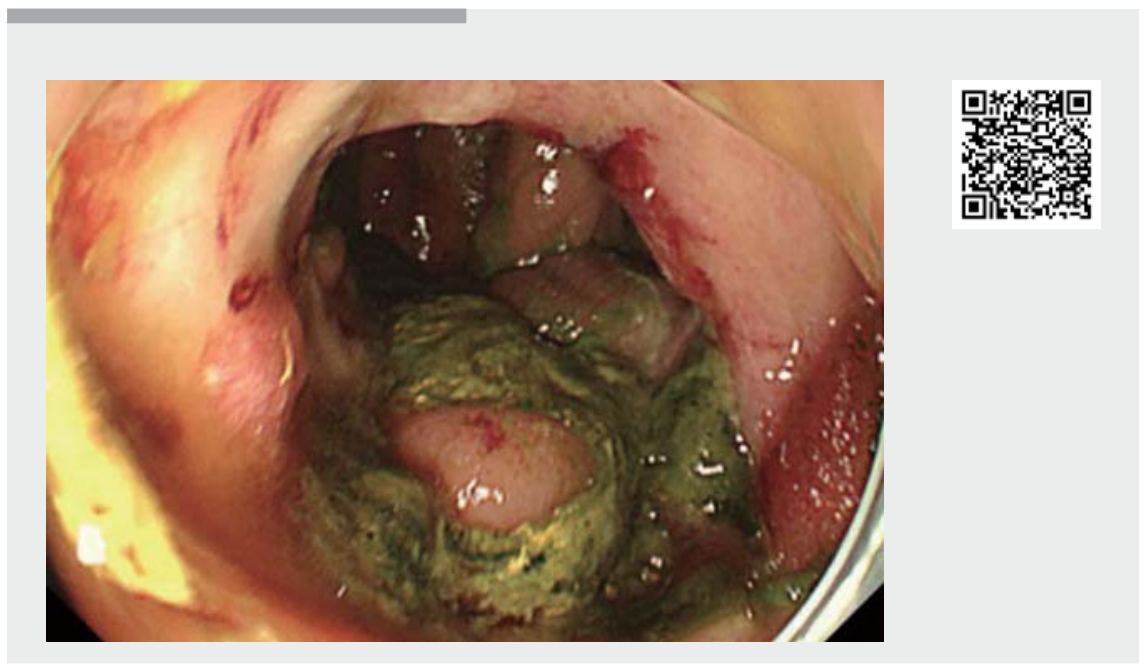

$\square$ Video 1 Closure of the large small-bowel enteroenteric fistula.

the first diagnosis. During the medication period, these symptoms were successfully relieved. However, he was readmitted to our hospital 1 week ago with complaints of refractory diarrhea and vomiting.

Physical examination was normal except for diffuse abdominal tenderness, whereas laboratory tests revealed hemoglobin $73 \mathrm{~g} / \mathrm{L}$, potassium $3.3 \mathrm{mmol} / \mathrm{L}$, sodium $128.6 \mathrm{mmol} / \mathrm{L}$, and albumin $13.7 \mathrm{~g} / \mathrm{L}$. After the patient's nutritional status had been improved, esophagogastroduodenoscopy was performed and showed a large fistula in the second portion of the duodenum ( $\mathbf{F i g . 1}$ ), extending to the jejunoileal lumen through the fistula tract (> Fig.2). A small-bowel enteroenteric fistula was diagnosed.

We used purse-string sutures, with an endoloop and hemostatic clips, to successfully close the fistula orifice ( $\triangleright$ Fig. 3 ,

- Video 1). The patient's symptoms resolved after the procedure, and he was switched to anti-tumor necrosis factor agents for further treatment.
Duodenal fistulas in patients with Crohn's disease are rare and surgical treatment is usually recommended [1]. To our knowledge, this is the first case report of a large small-bowel enteroenteric fistula successfully closed using pursestring sutures.

Endoscopy_UCTN_Code_TTT_1AO_2AI

\section{Acknowledgments}

This work was supported by the Natural Science Foundation of the Guangdong Province (No.2018A0303100024), Three Engineering Training Funds in Shenzhen (No.SYLY201718, SYJY201714 and SYLY201801), Technical Research and Development Project of Shenzhen (No.JCYJ20150403101028164), and Shenzhen Health Planning Commission (No. SZXJ2017030).

\section{Competing interests}

The authors declare that they have no conflict of interest. 
De-feng Li, Su-zhu Zhu, Zheng-lei Xu, Jun Yao

Department of Gastroenterology, the 2nd Clinical medicine College (Shenzhen People's Hospital) of Jinan University, Shenzhen, China

\section{Corresponding author}

\section{Li-sheng Wang, MD}

Department of Gastroenterology, The Second Clinical Medicine College (Shenzhen People's Hospital) of Jinan University, 1017 Dong men North Road, Luo hu District, Shenzhen 518020, P.R. China Fax: +86-755-25533118 wanglsszrmyy@163.com

\footnotetext{
${ }^{*}$ These authors contributed equally
}

[1] Tonkic A, Borzan V. Treatment of fistulizing Crohn's disease. Acta Med Croatica 2013; 67: 191-194

Bibliography

Endoscopy 2020; 52: E422-E423

DOI 10.1055/a-1149-1328

ISSN 0013-726X

published online 6.5.2020

(c) 2020. Thieme. All rights reserved.

Georg Thieme Verlag KG, Rüdigerstraße 14,

70469 Stuttgart, Germany

\section{ENDOSCOPY E-VIDEOS}

https://eref.thieme.de/e-videos

回回 Endoscopy E-Videos is a free 登视 靣解: on interesting cases and new techniques in gastroenterological endoscopy. All papers include a high quality video and all contributions are freely accessible online.

This section has its own submission website at https://mc.manuscriptcentral.com/e-videos 